"This is the peer reviewed version of the following article: [Journal of genetic counseling, 2019, 28, (5), pp. 1029-1041], which has been published in final form at [https://onlinelibrary.wiley.com/doi/abs/10.1002/igc4.1156]. This article may be used for noncommercial purposes in accordance with Wiley Terms and Conditions for Self-Archiving." 


\section{Family Communication Following a Diagnosis of Myotonic Dystrophy: To Tell or not to Tell?}

Shelby Taylor ${ }^{1,2,3}$, Miriam Rodrigues ${ }^{4,5}$, Gemma Poke $^{6}$, Samantha Wake ${ }^{1,2}$, Alison McEwen ${ }^{7}$

${ }^{1}$ The University of Melbourne, Australia

${ }^{2}$ Murdoch Children's Research Institute, Melbourne Australia

${ }^{3}$ The Royal Melbourne Hospital and Peter Mac Callum Cancer Centre, Melbourne Australia

${ }^{4}$ Neurology, Auckland District Health Board, New Zealand

${ }^{5}$ Muscular Dystrophy New Zealand

${ }^{6}$ Genetic Health Services New Zealand

${ }^{7}$ University of Technology Sydney, Australia

Correspondence

Shelby Taylor

Parkville Familial Cancer Centre and Genomic Medicine

Peter Mac Callum Cancer Centre and The Royal Melbourne Hospital

305 Grattan Street

Parkville. Victoria. 3052

$\mathrm{Ph}+61393427151$

Fax +6193424267

Shelby.taylor@petermac.org 


\begin{abstract}
Family communication about genetic information enables informed medical and reproductive decision-making. The literature suggests a significant proportion of genetically at-risk family members remain uninformed about genetic risk information as a result of non-disclosure. This study explored the experiences of New Zealand families communicating about a diagnosis of type 1 myotonic dystrophy (DM1). Eligible individuals were identified and recruited from the New Zealand (NZ) MD Prev study, a nationwide study which aimed to determine the prevalence, impact and costs of genetic muscle disorders across the lifespan. Twelve qualitative semi-structured interviews were conducted with 17 participants. The findings demonstrate diversity among and within families, with several distinct family narratives described. Most participants reported a motivation to tell relatives about their diagnosis to promote autonomy. Women were pivotal throughout communication processes and this was often tied to the concept of maternal responsibility and a desire to promote relatives' reproductive autonomy. The diagnosis of DM1 and the subsequent family communication decisions altered relationships for many, with both positive and negative impacts described. The findings demonstrate that individuals require time to explore the impact of a diagnosis of DM1 on self, family and intimate partner relationships to anticipate unique communication challenges. Genetic counsellors can use these findings to inform their approach to counselling families with DM1. Longitudinal genetic counselling may be beneficial as a way to provide individuals with life stage specific support as they communicate with their relatives about a diagnosis of DM1.
\end{abstract}

Key Words: Myotonic Dystrophy, Family Communication, Genetic Counselling, Genetics, Qualitative Study, Relationships 


\section{Background}

Genetic information is family information (Forrest et al., 2003; Gaff et al., 2007). When an individual is diagnosed with a genetic condition, genetic testing is often available to 'at-risk' relatives, to clarify their genetic status. Knowledge of a genetic condition may provide family members with a choice about whether or not they access genetic testing. The justification for family communication can be condition dependent. Justification for family communication may be based around availability of treatment or prevention of symptoms/disease in an individual with the condition, severity of disease, and age of onset. For a condition like myotonic dystrophy, knowledge allows for targeted symptom management (Laurent et al., 2011, Takeshima et al., 2018) and promotes reproductive choice.

Type 1 myotonic dystrophy (DM1) is a progressive and degenerative condition (MachucaTzili, Brook \& Hilton-Jones, 2005), most commonly associated with myotonia, progressive muscle weakness, and other multi-systemic implications affecting the brain, eyes, heart and endocrine system (Machuca-Tzili et al., 2005; Pavicevic et al., 2013). This condition is caused by a triplet repeat expansion of the base sequence ' $\mathrm{CTG}$ ' in the $D M P K$ gene, which is inherited in an autosomal dominant manner. The expansion is unstable between generations, particularly with maternal inheritance (Harley et al., 1993), resulting in generational anticipation. The normal range of 'CTG' repeats in individuals is 5-35 (Kamsteeg et al., 2012). Individuals with 38-49 repeats are considered to be pre-mutation carriers (Kamsteeg et al., 2012). Premutation carriers do not have a clinical phenotype, but they are at-risk of having a child with DM1, as repeat sizes within this range are vulnerable to expansion (Kamsteeg et al., 2012).

A correlation can be observed between the length of the repeat and the disease severity, meaning that DM1 generally is more severe and has an earlier age of onset with each 
successive generation (Machuca-Tzili et al., 2005). Age of onset can range from birth to later in adulthood, with variable clinical presentation. Individuals with DM1 can range from being mildly affected adults who may have cataracts or mild myotonia; to adults with a classical form which may include myotonia, muscle weakness, cardiac problems and diabetes; and newborns with a potentially life limiting congenital form resulting in hypotonia, breathing difficulties, and cognitive impairment. Women affected with DM1 are also more likely to develop polyhydramnios and a worsening of symptoms during pregnancy, specifically myotonia (Awater, Zerres \& Rudnik-Schoneborn, 2012; Johnson et al, 2015). Family communication is important in the context of DM1 as a number of the medical implications of DM1 can be effectively managed with knowledge and medical intervention, improving quality of life and reducing mortality (Laurent et al., 2011, Takeshima et al, 2018, Ashizawa et al., 2018). For example, individuals with myotonic dystrophy can have life threatening reactions to anesthetics and therefore careful monitoring and management is required when considering surgeries and general aesthetic use (Ashizawa et al., 2018). Individuals with DM1 are also susceptible to diabetes, and knowledge of the condition means individuals can undergo formal glucose tolerance testing, and can access treatment and implement lifestyle changes in a timely manner (Ashizawa et al., 2018). Knowledge of a genetic diagnosis in the family also enables individuals to make informed reproductive decisions, and may allow individuals to access government funded reproductive technologies in New Zealand, including preimplantation genetic diagnosis (PGD).

Various factors have been identified as having an impact on the tension that exists surrounding disclosure of genetic risk information within family units. While it is thought that non-disclosure is more frequently a passive outcome rather than an intentional act (Gaff, Collins, Symes \& Halliday, 2005), it is clear that most individuals at genetic risk do not receive sufficient information from their family members to be able to make an informed 
decision about accessing genetic testing (Menko et al., 2013). 'Closeness' of family relationships can both assist and hinder the process of communication (Forrest et al., 2003; McGinvern et al., 2004; Wilson et al., 2004). For individuals who withhold genetic risk information from their relatives, the most commonly reported explanation is not knowing a relative personally (d'Agincourt-Canning, 2001; Wilson et al., 2004; Mesters et al., 2005; Landsbergen et al., 2005). Disconnection and loss of contact resulting from divorce, separation and adoption have also been reported to impede family communication processes (Forrest et al., 2003; Healy et al., 2017). Personal views and feelings about communication and the utility of genetic testing can act to motivate or inhibit disclosure (Hamilton, Bowers \& Williams, 2005; d'Agincourt-Canning, 2001). Furthermore, emotional barriers have been described as restricting communication about genetic information (Forrest et al., 2003). Conversely, there are a number of factors which have been reported to promote family communication. The literature describes the important role that 'messengers' play in family communication. 'Messengers' are key individuals in families who take lead roles in disseminating genetic information in the family (Keenan et al., 2005; Wilson et al., 2004). Importantly, messengers may be unaffected relatives or partners (Wiens et al., 2013). Additionally, several studies have demonstrated a gender effect on disclosure of and communication about genetic information (d'Agincourt-Canning, 2001; Gaff et al., 2005; Hallowell et al., 2005; Finlay et al., 2008; Bruwer et al., 2013), whereby women are dominant in communication processes and are generally considered to be the 'gate-keepers' of genetic information (Keenan et al., 2006).

Genetic counselling plays an integral role in the delivery of best practice genetic healthcare. The Human Genetics Society of Australasia states that genetic counsellors have a role in offering clients "support and assistance in conveying genetic information to 'at-risk' relatives" (HGSA, 2008, p.6). Family systems theory suggests genetic health professionals 
should "encourage individuals, partners and their family members to anticipate the impact genetic information may have, specifically on ways of communicating and relating to each other” (Galvin \& Young, 2010, p.115). However, genetic health professionals generally do not contact an individual's relatives directly to inform them of their genetic risk, due to the practical, ethical and legal requirements to respect patient confidentiality and to support individual autonomy (Lee, 2013). New Zealand and international guidelines allow health professionals to disclose genetic information only in such circumstances whereby potential harm to the relative that could arise through non-disclosure is considered to be serious (Lee, 2013; Menko et al., 2013). While genetic health professionals can feel uneasy about the possibility of family members remaining unaware of their genetic risk, and often describe feeling a sense of responsibility towards clients' families (Bower et al., 2002; Dugan et al., 2003; Dheensa, Fenwick, Shkedi-Rafid, Crawford \& Lucassen, 2016), there are conflicting opinions in the literature as to whether and to what extent genetic services are responsible for notifying individuals of their genetic risk (Lehmann, Weeks, Biener \& Garber, 2000; Andorno, 2004; Suthers et al., 2006).

A number of intervention studies have demonstrated that genetic health professionals can have an impactful role in the notification of at-risk family members. The South Australian Clinical Genetic Service developed an intervention whereby genetic health professionals directly notified relatives at-risk of hereditary cancer conditions, by letter, without compromising the privacy of the proband (Suthers et al., 2006). After two years, the proportion of relatives per family who underwent predictive testing was $40 \%$ in the intervention group, as opposed to $23 \%$ in families who received standard care (Suthers et al., 2006). More recently, a telephone genetic counselling intervention was assessed in a randomised controlled trial (Hodgson et al., 2016). While no statistically significant difference was observed between the intervention cohort and the cohort who received 
standard care, more frequent contact of relatives with the genetics service was found in the intervention cohort in families where the genetic condition was associated with a higher risk to offspring (Hodgson et al., 2016).

While there is a significant amount of literature exploring the tension surrounding family communication about genetic information, these studies report conclusions from a limited number of genetic conditions and demographic contexts, with no studies exploring family communication in the setting of a diagnosis of myotonic dystrophy. Exploration of communication in families with DM1 provides insight into the ways in which individuals approach communication regarding an inherited muscular degenerative condition which has a range of symptoms, some of which can be managed with early diagnosis and treatment, thereby offering improved outcomes. Furthermore, no studies have been conducted exploring family communication within New Zealand; therefore this study contributes to the international perspective on family communication which is important in an increasingly global world. The aim of this study was to explore the experiences of New Zealand families communicating about a diagnosis of type 1 myotonic dystrophy.

\section{Methods}

A qualitative approach was taken to examine experiences of family communication for individuals with DM1. Ethics approval for the present study was granted by the Department of Health Sciences Human Ethics Sub-Committee at the University of Melbourne (HESC reference number 1748593).

\section{$\underline{\text { Setting }}$}

This study is a sub-study of a New Zealand-wide prevalence and impact study of genetic muscle disorders, MD Prev (Theadom et al., 2016). MD Prev aimed to determine the number 
of individuals diagnosed with a genetic muscle disorder living in New Zealand on the point prevalence date of $1^{\text {st }}$ April 2015. MD Prev collected histological and genetic verification of a diagnosis, as well as other medical and demographic information. Ethics approval for MD Prev was granted by the New Zealand Northern Health \& Disability Ethics Committee $(14 / \mathrm{NTB} / 118)$.

\section{$\underline{\text { Sampling }}$}

Purposive sampling was utilised to deliberately select participants with particular characteristics to enhance sample coverage. Demographic data held by the MD Prev study was utilised to select for: participants across different regions of New Zealand, gender balance, a mix of individuals who either had or had not been seen by a genetics service, and individuals of Māori descent.

\section{$\underline{\text { Recruitment }}$}

Participants were recruited from the MD Prev study. Inclusion criteria were that participants had received a diagnosis of type 1 myotonic dystrophy for themselves or for a child; had provided consent to being recontacted about future research opportunities; had the capacity to provide consent; were over the age of 18; and were able to participate in an English language interview. Some participants requested that a partner or unaffected parent also be present for the interview. Partners and parents provided consent to participate. Some individuals with DM1 had difficulty with speech, and therefore family members helped to communicate their experiences. For others, parents were central to communication processes and therefore individuals felt they should be present for the interview to capture the family's experience communicating the diagnosis of DM1. This was participant driven.

Thirteen participants were contacted by telephone or via email by an MD Prev researcher, 
MR, extending an invitation to take part. Twelve individuals who agreed to participate were contacted by ST and were emailed a participant information sheet, a consent form, and a suitable time and location for the interview were confirmed. Interviews were conducted between $03 / 17$ and 08/17.

\section{$\underline{\text { Procedures }}$}

Participant interviews focused on individuals' experiences of receiving a diagnosis of DM1 for themselves or for their child, and experiences with family communication following their diagnosis. The development of the interview guide was informed by evidence identified in the literature surrounding family communication about genetic conditions, and by the clinical experience of the research team. Interviews were audio recorded and transcribed verbatim. Transcripts were de-identified with pseudonyms used to protect the confidentiality of participants and their families. Transcripts were imported into NVivo 11 (QSR International Pty Ltd., Melbourne, Australia) for storage and management.

\section{$\underline{\text { Data Analysis }}$}

Thematic analysis was utilised to identify and extract themes directly from participant responses (Braun \& Clarke, 2013). The lead researcher read and critically analysed each transcript multiple times, searching for important ideas and documenting emergent themes. A coding scheme was then developed to capture important ideas emerging from the data and these were organised into categories from which themes were extracted. Theme development was an ongoing collaborative and reflexive process. Themes were compared across transcripts and in relation to characteristics purposively sampled for. Themes were then collaboratively discussed with ST, AM and SW and organised into concepts. Four transcripts were randomly selected and independently analysed by AM to cross check coding and 
interpretation of data. Transcripts were continually re-read and analysed for comparison as the coding system evolved with the emergence of new ideas in later transcripts.

\section{Results}

We interviewed 13 individuals with DM1, two unaffected parents, and two spouses. Table 1 summarises the participant demographics. Approximately $15 \%$ of the NZ population identify as being Māori, which is similar to our cohort (11\%). 'Pākehā' is a term used to describe New Zealanders of Caucasian descent.

\section{$\underline{\text { Participants }}$}

Twelve interviews were conducted. Eleven were conducted in person and one interview was conducted by telephone. Interview length varied from 60-140 minutes. Three participants had other family members present for the interview who provided consent to take part in this research, resulting in a total of 17 participants. In addition to the 12 individuals with DM1, two unaffected parents, two spouses and one son with DM1 over the age of 18 consented to participate.

\section{Table I. Participant Demographics}

In presenting the findings, verbatim quotes have been used as exemplars of the themes that emerged from thematic analysis. Pseudonyms have been used throughout participant quotes to protect the confidentiality of participants and their families. Although a number of themes were captured through this research, six key themes are presented below. 
The results presented were consistent across the demographic characteristics that were purposively sampled for, including ethnicity, region, and whether participants received a molecular diagnosis or a clinical diagnosis.

\section{Figure I. Summary of Themes}

\section{Diversity in Family Communication}

Participant narratives revealed the diversity in the way families approached communication about DM1. Some participants described that DM1 was talked about openly. "Everyone knows about it, everyone talks about it... It's not under the carpet, it's all out in the open. So there's never been a time where I had to go and say 'oh I've got muscular dystrophy'."

Participant 1, female with DM1

Others described that conversations about DM1 were actively avoided within their family. "It's like an unspoken thing. It's there, we don't talk about it though."

Participant 11, male with DM1

\section{To Tell or Not to Tell?}

The majority of participants reported that either they or a relative disclosed their diagnosis of myotonic dystrophy to immediate family members and to family members with whom they had close relationships. Although most individuals reported immediate family members were informed about the diagnosis, individuals described the emotional difficulties associated with being the 'messenger'. For example, one woman described the difficult task of informing her three sons following her husband's diagnosis of myotonic dystrophy.

"I knew that with that phone call it was going to change their lives (crying)...It was a hard 
one to make but I tried not to let them hear that in my voice. And ah of course there was the chance that they could have missed and they didn't have [DM1] so I was trying to, when I spoke to them I tried to promote that."

Participant 9, spouse and mother

A number of participants actively stepped past a 'gate-keeper' to ensure at-risk relatives were informed.

"My uncle Cam as I said, refusing point blank to discuss it at all. And his two kids who are old enough to start showing symptoms now, I sat them down last Christmas and talked to them about it, because he wouldn't. I said 'they have to know'."

Participant 4, female with DM1

Some participants described 'not telling' at least one immediate family member, or being on the receiving end of non-disclosure. Disconnection, stemming from estrangement, conflict, adoption and geographical distance were described as the key barriers to disclosure. For example, one woman described how disconnection stemming from an adoption that took place in her family introduced a barrier to communication.

“We don't want to be selfish and break up you know a happy family. So we just decided that we won't contact or get in contact with that side of the family."

Participant 6, female with DM1

Although most participants stated that immediate family members were actively told about their diagnosis of myotonic dystrophy, most participants assumed that information about their diagnosis had been communicated to extended family members.

"I don't think there's much point in bringing it up with [the extended family], uhm, unless they have it as well. It's more of a, they all know, uhm, well I'm pretty sure that they do." 


\section{The Role of Women in Communication}

The majority of participants described a key woman who was responsible for communication about genetic risk information within the family. Most female participants identified themselves or another female relative as this person.

“After we got Lucy's (daughter) diagnosis I thought, 'I'm going to tell all the cousins because that's what [the genetic service] is telling me to do.",

Participant 3, female with DM1 \& mother of a child with congenital DM1

Conversely, the majority of males did not disclose their diagnosis of myotonic dystrophy to at-risk relatives. Rather, wives, mothers and sisters were described as taking on this role in families.

"I told Lily (brother-in-law's wife) with a phone call so that she could tell Arnold (brotherin-law). And, uhm, I, uhm, I told Daisy (brother-in-law's wife) so that she would tell Brian (brother-in-law) and they told James (brother-in-law) so- and of course I told my own family."

Participant 9, spouse and mother

When describing ongoing communication about myotonic dystrophy, male participants described feeling more comfortable talking with female relatives in comparison to male relatives.

"My mum would be my first person I would go to...It's just we (father with DMI and son) don't talk about it. I don't think it is with me, but I think it is with older men, they're very 'I'll be fine'." 
Male participants also identified their female relatives as being responsible for engaging them with genetic health and prompting them to consider genetic testing. One participant described how his sister became aware of DM1 and subsequently alerted him to it, after she had gathered family history information for family planning purposes.

"She (sister) had done a lot of genealogy work on the family so she was more aware of, not the symptoms but the prevalence of it in my father's family. So whereas, I wasn't at all. I knew I had an uncle who was unwell, you know, who had it, and a cousin who had it but I thought, you know, I'm not in a wheelchair...If she hadn't prompted me to get tested I probably wouldn't have got tested until something like maybe the cataracts."

Participant 16, male with DM1

Furthermore, some male participants described encountering barriers to accessing genetic testing, despite being told about the presence of myotonic dystrophy in the family.

"She'd (sister) told me to go and get tested but never told me the right name so that I could go to my doctor... I said [to my doctor] 'you know this' and he said 'there's no such thing'. So I never had the correct name so I never got tested for it."

Participant 12, male with DM1

\section{Promoting Autonomy}

Many participants described the concept of autonomy when considering whether to share information about a diagnosis of myotonic dystrophy. Many participants described feeling motivated to inform family members so that their relatives could make informed reproductive decisions. 
“His (brother's) daughter is 17... She knows that Lucy has [DM1], so I hope that and, ah, she's not, she's very innocent you know. But I just hope that she's armed with the information to go and get tested down the line in ten years' time if she meets someone and wants to have kids, you know."

Participant 3, female with DM1 \& mother of a child with congenital DM1 One participant expands on the concept of reproductive autonomy motivating communication, linking this to the possibility of anticipation, and therefore congenital myotonic dystrophy.

"With the girls (cousins), if they had children, uhm, and they had it and didn't know it, their children could end up with, uhm, not only a worse but you can also get a congenital form, which causes brain retardation and developmental problems and all of that sort of thing. And often that's how families find out." Participant 4, female with DM1

The majority of participants described that they felt it was important to inform relatives about DM1 so that their family members could make informed medical decisions.

"I think it's really a duty to let people know, because they could also have the condition unbeknown and something could happen to them and they'll need medical attention. And maybe without the knowledge that there is this condition, uhm, it would be more difficult to treat and maybe not successful."

Participant 8, male with DM1

Two participants who had been on the receiving end of non-disclosure described feeling like control had been taken away from them by not being informed about the condition before making reproductive decisions. Both of these women had a child with myotonic dystrophy (one having a child with the congenital form) and both learnt after their pregnancies that 
myotonic dystrophy had been identified and known about in their families for some time prior. These women expressed decisional regret, describing how they would have made different reproductive decisions, had they known about myotonic dystrophy. "I definitely wouldn't have tried to get pregnant naturally. I got married and then 2007 we were only 2 or 3 months and then I got pregnant and you just think everything is you know, is just going to all go like everything else went you know before. But, I feel like some of that control was taken away by the, that family, not telling us."

Participant 3, female with DM1 \& mother of a child with congenital DM1

"1: So she (paternal grandmother) told mum that there was nothing...

2: Which is a shame really because we could have...

1: You could have avoided having me?

2: Hey?

1: You could have avoided having me?

2: Yeh, well, yeh (silence)."

Participant 1, female with DM1 \& Participant 2, mother

\section{Feeling like communication decisions altered family relationships}

Some participants described that relationships had been impacted by decisions to disclose or withhold information about myotonic dystrophy within the family. Some participants explained that disclosure negatively impacted particular family relationships. "I don't think he (brother) likes seeing me anymore (crying) because I remind him. So he's more, he doesn't visit as often as he used to. Uhm, he doesn't want to be reminded, and it's possible that he or his children have it... I think that, ah, when he thinks of me, he thinks of DM1 and he really doesn't want to be reminded that it's in the family." 
Others described feeling like disclosure strengthened relationships with particular family members.

"I think I had a good relationship with my mother and it's probably strengthened my one with my sister."

Participant 16, male with DM1

Only negative implications were described as a result of non-disclosure.

"I’ve never spoken to them since."

Participant 3, female with DM1 \& mother of a child with congenital DM1

Some participants described that decisions to inform a partner about DM1 resulted in a strain or breakdown of an intimate partner relationship.

"People have a change of heart. My partner said he doesn't know if he could look after me after [the diagnosis]. Which I understood cos I said, you know, 'if you want to back out now, now's your chance to if you don't think you can handle it. '... Basically he doesn't want to see me deteriorate and stuff like that ...he said it would be too hard for him."

Participant 6, female with DM1

One participant described a strained relationship with her partner as a result of miscommunication, leading to a misunderstanding about her diagnosis.

"The only person was my husband. And, uhm, I told him really early, really early on in our relationship but he says I didn't....He doesn't remember but anyway, I kept saying to him 'You know my Dad, I'm going to be like Dad.' But he couldn't believe it. He [would say] 'But 
you're not like your Dad.' He couldn't believe it cos I was normal and he couldn't see it, uhm, but of course it's happened. He can see it now."

Participant 1, female with DM1

Some participants, who did not have partners, were concerned about driving a partner away in the future by disclosing their diagnosis of DM1.

"Like, in the future, like, when I get married or whatever it would be something that my wife would have to, it would be something that I would have to explain to my wife about...I'd have to explain it and if I explained it wrong you know it could potentially drive them away."

Participant 10, male with DM1

Furthermore, participants described the need to tell a future partner about their diagnosis, as they recognised partners would likely become their future carers. One man described the complexities of these discussions due to the additional pressures a diagnosis of DM1 places on intimate partner relationships.

"If I was thinking about getting married, I would have to tell the person that I was thinking about getting married with, before they said yes. You know, 'this is what you are going to be in for. You know, in ten years, you are probably going to spend the last five years of my life caring for me. And I may not be in the position to care for you.",

Participant 16, male with DM1

\section{Minimising Narratives}

The majority of participants described narratives whereby individuals compared their own diagnosis to other 'problems' which they perceived to be worse. These narratives minimised the potential severity of myotonic dystrophy.

"There's worse things than what I've got, you know. People have got worse conditions. Polio 
and they can never walk properly for the whole of their lives. Parkinson's is not very nice I mean, you know, there's all sorts of things. I could be worse off, you know."

Participant 1, female with DM1

A number of participants compared their diagnosis to Duchenne Muscular Dystrophy specifically, which they perceived to be 'worse'.

"There's a lot of muscular dystrophies out there that are worse than mine. Like the kids who have got Duchenne's, they don't live very long."

Participant 13, female with DMI

Interwoven with these minimizing narratives was the idea that families needed to 'get on with life' following a diagnosis of myotonic dystrophy.

"When my nephew was alive...he just kept talking about it and talking about it and talking about it. It used to annoy me because I mean if you've got it you've got it and you just need to get on with life and do what you can, you know. But, uhm, we don't talk about it."

Participant 17, female with DM1

\section{Discussion}

This study sought to explore the experiences of communication in New Zealand (NZ) families following a diagnosis of myotonic dystrophy (DM1), to gain insight into the factors influencing communication about genetic risk information. This is the first study exploring the experiences of family communication about DM1, and also the first to explore family communication within a New Zealand population. The results identified that NZ families' approach to communication about DM1 varies, depending on their unique experience of DM1. While most participants reported that either they or a female relative told immediate 
family members about their diagnosis, they assumed this information had then been communicated to the wider family. In keeping with the wider literature, this research reinforced the pivotal role of women as 'messengers' of genetic information within families. When considering motivations to disclose information about a diagnosis of DM1, participants consistently described the importance of promoting medical and reproductive autonomy of family members. Importantly, communication decisions had both positive and negative impacts on family and intimate partner relationships.

Participant narratives revealed the diverse approaches of communicating about DM1 both within and among New Zealand families. Some families valued openness, and others avoided discussion about DM1. This observation is consistent with other studies exploring family communication about genetic or health issues (Mellon et al., 2006; Dancyger et al., 2011). It is logical that diversity exists in the way families approach communication, as families themselves are unique and will experience change in different ways. DM1 is a variable condition even within the same family, and therefore family members may experience DM1 in vastly different ways too. As well as the unique experience of DM1, pre-existing family dynamics and cohesiveness, gender and communication values contributed to the diverse narratives about myotonic dystrophy within and among New Zealand families.

In this cohort, participants described clearly defined expectations about how they should talk about myotonic dystrophy within the family. Beliefs and understandings about 'appropriate communication' evolve within family units and act to maintain communication through coordination of "oughts" and "shoulds" (Bylund, Galvin \& Gaff, 2010, p.9). One woman commented 'everyone talks about it' and therefore recognised that openness was a shared communication value in her family. In comparison a male participant described that his diagnosis of DM1 was 'like an unspoken thing, ' suggesting that relatives were aware of his 
diagnosis although there was an expectation that this was not to be discussed in an ongoing manner. It was not explicitly stated that authoritative family figures determined communication behaviours, as has been suggested by other studies (Forrest et al., 2003; Plumridge et al., 2010). Rather, participants in this study 'learnt' communication expectations through their own experiences of discomfort after going against the grain, or through observing the communication behaviours of other family members.

Consistent with the literature, most participants described that immediate family members were actively told about DM1, while it was often assumed that extended relatives had been informed by independent family members. A number of studies have reported that individuals are more likely to disclose genetic risk information to first degree relatives, and to relatives with whom individuals feel stronger emotional bonds (Claes et al., 2003; Peterson et al., 2003; Coates et al., 2007). Although participants described the task of informing relatives about DM1 as being emotionally burdensome, they recognised the importance of communication. Demonstrating this point further, a number of women reported actively stepping past a gate-keeper in the family, to ensure relatives in the next generation were told as they approached reproductive age.

Women were central to family communication about DM1, even when DM1 was on their partner's side of the family. This was in contrast to male participants, who did not identify themselves as 'messengers'. The role of women in communicating and managing family health information is a phenomenon that has been well recognised (d'Agincourt-Canning, 2001; Foster et al., 2004). While both males and females in this study were aware of the implications of their diagnosis for family members, males reported experiencing greater discomfort in talking about this with their family members and described a reliance on female relatives. In this cohort, females were primarily responsible for informing at-risk relatives. It 
seemed that this 'gendered' approach to communication was implicit and deemed to be appropriate within families.

The concept of women being more likely to communicate genetic test results with their relatives, compared to men, has been observed in other studies (d'Agincourt- Canning, 2001; Forrest et al., 2003; Gaff et al., 2005; Finlay et al., 2008; Bruwer et al., 2013). It has been proposed that societal gender constructs impose stronger moral obligations on women to take on the 'messenger' role, through expectations of being 'carers' (d'Agincourt-Canning 2001; Foster et al., 2004). This gendered obligation was not explicitly stated by participants in this study; rather, most participants described intrinsic understandings that females facilitated communication about DM1 within families. Gender expectations may intersect with communication in the opposite sense, encouraging males to adopt the belief of 'strength in silence' (Foster et al., 2004, p. 452). It follows that although women described emotional difficulties accompanied with disclosing genetic information, these conversations seemed more natural to women. This concept is in keeping with the conclusions of another study exploring family communication about Lynch Syndrome, which identified that women felt it was 'normal' to communicate about genetic issues, while men did not (Gaff et al., 2005).

Engagement with genetic health services appeared to be another gendered activity in this cohort. This is consistent with observations in the broader healthcare setting, where women are more likely to engage with healthcare services than men (Stefan, 2015; Wellstead, 2011). Male participants were commonly encouraged to have genetic testing by another female relative and seemed to be more easily deterred from engaging with genetic health services. For example one male participant described that his sister told him about the condition in his family but he did not have the 'correct name', which prevented him from seeking genetic testing. This may provide insight as to why uptake of genetic testing is generally lower in 
men (McAllister et al., 1998; Finlay et al., 2008). Women in this study, on the other hand, were more likely to advocate for themselves and their families, taking control of the communication process to ensure 'at-risk' relatives were informed.

Autonomy was consistently described by participants when considering whether to disclose information about their diagnosis of DM1 to family members. Participants recognised the importance of equipping relatives with information about their diagnosis of DM1, particularly in the context of reproductive decision making and medical management. While this was described by most participants, males generally did not act on this motivator themselves; rather, a female 'messenger' did.

Women in this study commonly associated communication decisions with potential pregnancy outcomes of other relatives. This concept went a step further for some women, who described feeling a sense of responsibility for the potential outcomes of other relatives' communication decisions, encouraging a number of women to step past a 'gate-keeper.' For example, participant 4 described feeling a responsibility to inform her female cousins so they could make informed reproductive decisions. The literature commenting on gender roles and responsibilities in relation to pregnancy (Rapp, 2000; Ettore, 2000), describes the societal notion that women are responsible for maintaining the health of a pregnancy and in turn 'take responsibility if things go wrong' (Reed, 2007, p. 344). Women receive strong social and medically driven messages encouraging information seeking and adoption of healthy behaviours prior to and throughout a pregnancy, instilling the concept of maternal responsibility (Rapp, 2000). Although DM1 affects men and women equally in a medical sense, women are faced with greater reproductive risks associated with pregnancy. One could therefore propose that the reproductive risks associated with being a female with DM1 or having a child with DM1 instill a stronger sense of responsibility towards disclosure in 
women compared to men. The findings of this study build on the concept of gendering of responsibility in pregnancy, suggesting that maternal responsibility has a role in communication about genetic risk information.

Although non-disclosure was not a commonly reported outcome, the implications of nondisclosure were significant in this cohort: it severed relationships and frustrated reproductive choice. Both participants who were on the receiving end of non-disclosure felt 'control was taken away' when making reproductive decisions, and both stated they wouldn't have chosen to conceive 'naturally' had they known about DM1. Furthermore, both women went on to have another child after learning about DM1, either through Pre-implantation Genetic Diagnosis (PGD) or adoption. These narratives were powerful, leading one to consider the impact of non-disclosure on parent-child relationships when reproductive autonomy has been impeded. The realisation of frustration of reproductive choice is exposed in the narrative between a mother (2) and daughter (1), where participant 1asks 'You could have avoided having me?' to which her mother responds 'Yeh, well, yeh.' This brief exchange reveals a now spoken knowledge that this woman is here because her parents did not know there was a choice. Very little is known about the long term impact of non-disclosure on these relationships, however these narratives demonstrate the ethical tension that exists between individual autonomy and the rights of the wider family to be informed about genetic risk information. Frustration of reproductive autonomy has been described as a result of nondisclosure in the literature, and some individuals have legally challenged that non-disclosure and the potential role of health professionals involved is a form of 'actionable negligence' and a violation of Human Rights (Chico, 2016).

Decisions to tell or withhold information about DM1 altered family relationships and dynamics significantly for some participants in this study. Some participants described that 
disclosure had strengthened relationships with family members. The genetic counselling literature suggests that disclosure can provide avenues for social and emotional support, which can have the effect of strengthening relationships (d'Agincourt-Canning, 2001; Wilson et al., 2004). However, some participants described that disclosure about DM1 had weakened family relationships. One participant described how his brother no longer visits or contacts him as he 'does not want to be reminded.' It seems that disclosure can create tension and a sense of disconnection within family units, particularly between family members who have opposing coping styles (Speice, McDaniel, Rowley \& Loader, 2002).

Although this study did not specifically aim to explore communication about DM1 with a spouse, a number of participants raised this as being a challenging task, carrying significant impact. Several authors have acknowledged the importance of openness and self-disclosure in the development of healthy intimate relationships (Dindia, 2002; Troy \& Lewis-Smith, 2006; Hoskins et al., 2008). Although most participants reported that they had or theoretically would disclose their diagnosis to a partner, individuals commented on the complexities of this communication and recognised that this could be life changing, fearing the potential impact on relationships. Some participants reported that the decision to tell their partner about their diagnosis of DM1 resulted in the breakdown of a relationship. Others described how tension had evolved within their relationship from a misunderstanding arising from communication about DM1. Furthermore, a number of participants who did not have a partner stated that they anticipated telling a partner about their diagnosis would be a difficult task, with one man fearing this would 'drive them away'. Participants acknowledged that DM1 placed unique pressures on intimate relationships. For example, one participant attributed the breakdown of her relationship to the degenerative nature of DM1, with her partner saying that he would find it emotionally too difficult to witness her 'deteriorate'. Similarly, others mentioned that the reality of their partner needing to become their carer in 
the future placed practical pressures on their relationship.

Minimising narratives about DM1 seemed to evolve within families as a way to cope with the challenges posed by this condition. The majority of participants described narratives which minimised the effect of DM1 and encouraged families to 'get on with life.' Narrative formation can have an important role in families learning to adapt to life after a diagnosis (Biesecker \& Erby, 2008; Trees et al., 2010). Interestingly, narratives of 'it could be worse' demonstrated a mechanism of adaption for participants in this study, as they compared their situation to individuals with other conditions which they perceived to be worse, reminding themselves that they were 'lucky'. It seems that participants and their families learnt to cope and adapt to DM1 by 'shifting comparison standards' (Biesecker \& Erby, 2008). However, these narratives seemed to neglect an acknowledgement that DM1 could indeed be severe. One could not help but recognise that the impact of DM1 on participants seemed to be far more significant than what these narratives encapsulated. For example, the majority of participants in this study had experienced significant loss as a result of DM1, whether this be the loss of their health; the loss of a parent, child, extended relative, pregnancy; or the loss of choice. Furthermore, narratives about needing to 'get on with life' seemed to encourage individuals to move on from these losses, rather than 'dwell' on them by talking. One could therefore argue that minimising narratives might have the effect of restricting ongoing communication about DM1 within families.

\section{Practice Implications}

Based on the findings of this study, it is clear that reproductive decision making is a driving factor for communication about DM1 within families. When individuals know about DM1 in the family, they can access genetic testing to clarify their gene status, allowing individuals to make informed choices about family planning and reproductive options. Genetic counsellors 
have a crucial role in providing patient and family centered information and psychosocial support, to facilitate family communication and therefore to promote informed medical and reproductive decision making in the wider family. The findings of this small, exploratory study suggest that there may be value in longitudinal genetic counselling support, appropriate to an individual's life stage. Individuals may require additional genetic counselling support as they, or other family members, approach reproductive age.

Furthermore, these findings reveal the challenges that can emerge from communicating about a diagnosis of DM1 with a spouse. Pre-test genetic counselling should explore spousal relationships and encourage patients to consider the possibility of changes in established relationships. Spouses may benefit from attending pre-test genetic counselling sessions, to anticipate some of the ways DM1 may impact intimate partner relationships and to explore future decision making. Counselling should also encourage un-partnered individuals to consider having to tell a new partner in the future. Genetic counsellors should be aware unaffected spouses can be central to family communication processes, and therefore it is important spouses have access to individual and family centred information about DM1, and are offered practical and psychosocial support from genetic counsellors.

Lastly, these findings demonstrate that males who access genetic health services would likely benefit from ongoing genetic counselling support to facilitate dissemination of genetic risk information. Additional efforts may be required to engage males with genetic health services and this should be considered when meeting with male patients and with individuals who have male relatives. 
Gene carrier review programs should be considered as a model of care to provide the ongoing genetic counselling support to actively work with families regarding family communication and medical management. Clinical gene carrier review programs could provide a framework to ensure individuals are able to access life stage specific genetic counselling support, particularly prior to family planning and pregnancy.

\section{Study Limitations}

This study design involved interviewing an individual or select family members, thereby neglecting the wider family perspective. Narratives about family communication and DM1 may be different or conflicting between family members. It would therefore have been helpful to explore the perspectives of multiple members of the same family in interviews. This being said, the literature acknowledges that "family members' behaviours serve as indicators of the overall family themes" (Bylund et al., 2010, p.9) and therefore an individual's narrative is likely to capture a broader family narrative.

Although qualitative methodologies allow the collection of rich, experiential data, the nature of this research means that the findings are not generalizable. Nevertheless, they provide health professionals and researchers with an in-depth insight into the experiences of a select number of New Zealanders and their families communicating about DM1.

Myotonic dystrophy is a variable condition, which can be associated with variable levels of cognitive impairment in some individuals. The inclusion criteria for the present study meant individuals had to have capacity to provide consent in order to be eligible. One could propose that cognitive impairment could introduce barriers to family communication, however this was not explored in the present study. 


\section{Research Recommendations}

A number of participants in this study raised the issue of disclosure of genetic risk information with a partner, without being prompted by the interview guide. Due to the degenerative nature of DM1 and the possible reproductive implications, individuals are faced with a unique set of challenges when disclosing their diagnosis to a partner. Further research is needed to address how individuals navigate these challenges and whether gender roles intersect with this process.

One could speculate that the presence of minimising narratives within family units may reduce individuals' perception of their genetic risk, however this remains unclear. Further research is required to better understand the impact of families employing minimising narratives to communicate about genetic risk information, specifically considering risk perception of relatives.

\section{Conclusion}

This study explored family communication in a group of New Zealand individuals who have a clinical/molecular diagnosis of DM1, using in-depth interviews. The findings demonstrate the diversity among and within families, with several different family narratives about DM1 described. The majority of participants described a motivation to tell relatives about DM1, to promote autonomy by facilitating targeted healthcare and reproductive choice. The findings support the central role many women play as holders and communicators of family health information, and build on the concept of gendering of responsibility, suggesting that maternal responsibility and a desire to promote relatives' reproductive autonomy motivates women to take on the messenger role in families. Participants described how the presence of DM1 in 
the family, and in themselves, altered family relationships. Most families adopted narratives that minimised the impact of DM1, demonstrating how family narratives and ongoing communication present coping strategies to adapt to and process the challenges imposed by DM1. Genetic counselling should be offered to all individuals receiving a diagnosis of DM1 and to those considering predictive testing. DM1 presents unique challenges within families following a diagnosis and throughout the process of communication. Individuals require time and life stage appropriate support to explore these unique challenges to maximise individual and family well-being and autonomy. The findings of this small, exploratory study suggest that there may be value in longitudinal genetic counselling, perhaps as part of a multidisciplinary management clinic.

Authors Shelby Taylor, Miriam Rodrigues, Gemma Poke, Samantha Wake and Alison McEwen declare they have no conflict of interest.

\section{Human Studies and Informed Consent}

All procedures followed were in accordance with the ethical standards of the responsible committee on human experimentation (institutional and national) and with the Helsinki Declaration of 1975, as revised in 2000 (5). Informed consent was obtained from all participants being included in the study.

The listed authors all met the ICMJE criteria for authorship.

Shelby Taylor made substantial contributions to the study design, and the acquisition, analysis and interpretation of data. Shelby Taylor drafted the work. 
Miriam Rodrigues and Gemma Poke made substantial contributions to the conception of the work. Both authors also made significant contributions throughout the drafting process, both revising it critically for important intellectual content.

Samantha Wake made substantial contributions to the study design and the acquisition and interpretation of data for the work. Samantha Wake also provided content expertise throughout the drafting process, and critically revised the work.

Alison McEwen made substantial contributions to the design of the work and to the analysis and interpretation of data for the work. Alison McEwen contributed significantly to the drafting of the work and provided expertise while critically revising.

All authors approved the final draft and agree to be accountable for all aspects of the work. 


\section{References}

Andorno, R. (2004). The right not to know: an autonomy based approach. Journal of Medical Ethics, 30(5), 435-439. doi: http://dx.doi.org/10.1136/jme.2002.001578

Awater, C., Zerres, K., \& Rudnik-Schoneborn, S. (2012). Pregnancy course and outcome in women with hereditary neuromuscular disorders: comparison of obstetric risks in 178 patients. European Journal of Obstetrics, Genecology, and Reproductive Biology, 162(2), 153-159.

Ashizawa, T., Gagnon, C., Groh, W.J., Gutmann, L., Johnson, N.E., Meola, G.,...Winblad, S. (2018). Consensus-based care recommendations for adults with myotonic dystrophy type 1. Neurology Clinical Practice, 8(6), 507-520. doi:10.1212/CPJ.0000000000000531

Biesecker, B., \& Erby, L. (2008). Adaptation to living with a genetic condition or risk: minireview. Clinical Genetics, 74(5), 401-407. doi: 10.1111/j.1399- 0004.2008.01088.x

Bower, M. A., Veach, P. M., Bartels, D. M., \& LeRoy, B. S. (2002). A survey of genetic counselors' strategies for addressing ethical and professional challenges in practice. Journal of Genetic Counseling, 11(3), 163-186.

Braun, V. \& Clarke, V. (2013). Successful qualitative research: a practical guide for beginners. London: Sage.

Bruwer, Z., Futter, M., \& Ramesar, R. (2013). Communicating cancer risk within an African context: experiences, disclosure patterns and uptake rates following genetic testing for Lynch syndrome. Patient Education and Counseling, 92(1), 53-60. doi: 10.1016/j.pec.2013.02.001

Bylund, C. L., Glavin, K. M. \& Gaff, C. L. (2010). Principles of family communication. In C. L. Gaff \& C. L. Bylund. (Eds.), Family Communication About Genetics (pp. 3-17), New York, NY: Oxford University Press.

Chico, V. (2016). Non-disclosure of genetic risks: the case for developing legal wrongs. Medical Law International, 16(1-2), 3-26. doi: http://doi.org/10.1177/0968533216653440 
Claes, E., Evers-Kiebooms, G., Boogaerts, A., Decruyenaere, M., Denayer, L., \& Legius, E. (2003). Communication with close and distant relatives in the context of genetic testing for hereditary breast and ovarian cancer in cancer patients. American Journal of Medical Genetics A, 116A(1), 11-19. doi: 10.1002/ajmg.a.10868

Coates, N., Gregory, M., Skirton, H., Gaff, C., Patch, C., Clarke, A., \& Parsons, E. (2007). Family communication about cystic fibrosis from the mother's perspective: an exploratory study. Journal of Research in Nursing, 12(6), 619-634. doi: $10.1177 / 1744987107083594$

d'Agincourt-Canning, L. (2001). Experiences of genetic risk: disclosure and the gendering of responsibility. Bioethics, 15(3), 231-247.

Dancyger, C., Wiseman, M., Jacobs, C., Smith, J. A., Wallace, M., \& Michie, S. (2011). Communicating BRCA1/2 genetic test results within the family: a qualitative analysis. Psychology \& Health, 26(8), 1018-1035. doi: $10.1080 / 08870446.2010 .525640$

Dheensa, S., Fenwick, A., Shkedi-Rafid, S., Crawford, G., \& Lucassen, A. (2016). Healthcare professionals' responsibility to patients' relatives in genetic medicine: a systematic review and synthesis of empirical research. Genetics in Medicine, 18(4), 290-301. doi: http://doi.org/10.1038/gim.2015.72

Dindia, K. (2002). Self-disclosure research: knowledge through meta-analysis. In M. Allen, R. W. Preiss, B. M. Gayle, \& N. A. Burrell (Eds.), LEA's communication series. Interpersonal communication research: Advances through meta-analysis (pp. 169185). Mahwah, NJ, US: Lawrence Erlbaum Associates Publishers.

Dugan, R. B., Wiesner, G.L., Juengst, E.T., O'Riordan, M., Matthews, A.L., \& Robin, N.H. (2003). Duty to warn at-risk relatives for genetic disease: genetic counselors' clinical experience. American Journal of Medical Genetics Part C: Seminars in Medical Genetics, 119C(1), 27-34.

Ettore, E. (2000). Reproductive, genetics, gender and the body; "Please doctor, may I have a normal baby?" Sociology, 34(3), 403-420. 
Finlay, E., Stopfer, J. E., Burlingame, E., Evans, K. G., Nathanson, K. L., Weber, B. L.,...Domchek, S. M. (2008). Factors determining dissemination of results and uptake of genetic testing in families with known BRCA1/2 mutations. Genetic Testing, 12(1), 81-91. doi: 10.1089/gte.2007.0037

Forrest, K., Simpson, S. A., Wilson, B. J., van Teijlingen, E. R., McKee, L., Haites, N., \& Matthews, E. (2003). To tell or not to tell: barriers and facilitators in family communication about genetic risk. Clinical Genetics, 64(4), 317-326.

Foster, C., Eeles, R., Ardern-Jones, A., Moynihan, C., \& Watson, M. (2004). Juggling roles and expectations: dilemmas faced by women talking to relatives about cancer and genetic testing. Psychology \& Health, 19(4), 439- 455. doi:

$10.1080 / 08870440410001684168$

Gaff, C. L., Clarke, A. J., Atkinson, P., Sivell, S., Elwyn, G., Iredale, R.,...Edwards, A. (2007). Process and outcome in communication of genetic information within families: a systematic review. European Journal of Human Genetics, 15(10), 9991011.

Gaff, C. L., Collins, V., Symes, T., \& Halliday, J. (2005). Facilitating family communication about predictive genetic testing: probands' perceptions. Journal of Genetic Counseling, 14(2), 133-140. doi: 10.1007/s10897-005- 0412-3

Hallowell, N., Ardern-Jones, A., Eeles, R., Foster, C., Lucassen, A., Moynihan, C., \& Watson, M. (2005). Communication about genetic testing in families of male BRCA1/2 carriers and non-carriers: patterns, priorities and problems. Clinical Genetics, 67(6), 492-502. doi:10.1111/j.1399-0004.2005.00443.x

Hamilton, R. J., Bowers, B. J., \& Williams, J. K. (2005). Disclosing genetic test results to family members. Journal of Nursing Scholarship, 37(1), 18-24. doi:10.1111/j.15475069.2005.00007.x

Harley, H. G., Rundle, S. A., MacMillan, J. C., Myring, J., Brook, J. D., Crow, S., ...Harper, P. S. (1993). Size of the unstable CTG repeat sequence in relation to phenotype and parental transmission in myotonic dystrophy. American Journal of Human Genetics, 52(6), 1164-1174. 
Healey, E., Taylor, N., Greening, S., Wakefield, C. E., Warwick, L., Williams, R., \& Tucker, K. (2017). Quantifying family dissemination and identifying barriers to communication of risk information in Australian BRCA families. Genetics in Medicine. Advance online publication. doi: 10.1038/gim.2017.52

Hodgson, J., Metcalfe, S., Gaff, C., Donath, S., Delatycki, M. B., Winship, I., Skene, L., Aitken, M., \& Halliday, J. (2016). Outcomes of a randomised controlled trial of a complex genetic counselling intervention to improve family communication. European Journal of Human Genetics, 24(3), 356-360. doi: 10.1038/ejhg.2015.122

Hoskins, L. M., Roy, K., Peters, J. A., Loud, J. T., \& Greene, M. H. (2008). Disclosure of positive BRCA1/2-mutation status in young couples: the journey from uncertainty to bonding through partner support. Families, Systems \& Health : The Journal of Collaborative Family Healthcare, 26(3), 296-316. doi: 10.1037/a0012914

Human Genetic Society of Australasia (HGSA). (2008). Process of genetic counselling. Retrieved from https://www.hgsa.org.au/documents/item/13.

Johnson, N. E., Hung, M., Nasser, E., Hagerman, K. A., Chen, W., Ciafaloni, E., \& Heatwole, C. R. (2015). The impact of pregnancy on myotonic dystrophy: a registrybased study. Journal of Neuromuscular Diseases, 2(4), 447-452. doi:10.3233/JND150095

Landsbergen, K., Verhaak, C., Kraaimaat, F., \& Hoogerbrugge, N. (2005). Genetic uptake in BRCA-mutation families is related to emotional and behavioral communication characteristics of index patients. Familial Cancer, 4(2), 115- 119. doi: 10.1007/s10689-004-7991-2

Kamsteeg, E. J., Kress, W., Catalli, C., Hertz, J. M., Witsch-Baumgartner, M., Buckley, M. F., ...Scheffer, H. (2012). Best practice guidelines and recommendations on the molecular diagnosis of myotonic dystrophy types 1 and 2. European Journal of Human Genetics, 20(12), 1203-1208. doi:

http://www.nature.com/ejhg/journal/v20/n12/suppinfo/ejhg2012108s1.html

Keenan, K. F., Simpson, S.A., Wilson, B.J., van Teijlingen, E.R., Mckee, L., Haites, N., \& Matthews, E. (2005). 'It's their blood not mine': who's responsible for (not) telling 
relatives about genetic risk? Health Risk \& Society, 7(3), 209- 226.

Laurent, V., Pellieux, S., Corcia, P., Magro, P., Pierre, B., Fauchier, L.,...Babuty, D. (2011). Mortality in myotonic dystrophy patients in the area of prophylactic pacing devices. International Journal of Cardiology, 150(1), 54- 58. doi: 10.1016/j.ijcard.2010.02.029

Lee, J. (2013). "Serious" but not "imminent"; genetics and the disclosure of health information to at risk relatives. New Zealand Medical Journal (online), 126(1377), 59-64.

Lehmann, L. S., Weeks, J. C., Klar, N., Biener, L., \& Garber, J. E. (2000). Disclosure of familial genetic information: perceptions of the duty to inform. The American Journal of Medicine, 109(9), 705-711. doi: https://doi.org/10.1016/S0002-9343(00)00594-5

Machuca-Tzili, L., Brook, D., \& Hilton-Jones, D. (2005). Clinical and molecular aspects of the myotonic dystrophies: A review. Muscle Nerve, 32(1), 1-18. doi:10.1002/mus.20301

McAllister, M., Evans, G., Ormiston, W., \& Daly, P. (1998). Men in breast cancer families: a preliminary qualitative study of awareness and experience. Journal of Genetic Counselling, 35(9), 739-744.

McGivern, B., Everett, J., Yager, G.G., Baumiller, R.C., Hafertepen, A., Saal, H.M. (2004). Family communication about positive BRCA1 and BRCA2 genetic test results. Genetics in Medicine, 6(6), 503-509.

Mellon, S., Berry-Bobovski, L., Gold, R., Levin, N. and Tainsky, M. A. (2006). Communication and decision-making about seeking inherited cancer risk information: findings from female survivor-relative focus groups. Journal of the Psychological, Social and Behavioral Dimensions of Cancer, 15(3), 193- 208. doi:10.1002/pon.935

Menko, F. H., Aalfs, C. M., Henneman, L. Stol, Y., Wijdenes, M., Otten, E.,...Tibben, A. (2013). Informing family members of individuals with Lynch Syndrome: a guideline for clinical geneticists. Familial Cancer, 12(2), 319. doi:10.1007/s10689- 013-9636-9

Mesters, I., Ausems, M., Eichhorn, S., \& Vasen, H. (2005). Informing one's family about genetic testing for hereditary non-polyposis colorectal cancer (HNPCC): a 
retrospective exploratory study. Familial Cancer, 4(2), 163-167. doi: 10.1007/s10689-004-7992-1

NVivo qualitative data analysis Software; QSR International Pty Ltd. Version 11, 2015.

Pavicevic, D., Miladinovic, J., Brkusanin, M., Svikovic, S., Djurica, S., Brajuskovic, G., \& Romac, S. (2013). Molecular genetics and genetic testing in DM1 Type 1. BioMedical Research International, 2013. Retrieved from https://www.hindawi.com/journals/bmri/2013/391821/

Peterson, S. K., Watts, B. G., Koehly, L. M., Vernon, S. W., Baile, W. F., Kohlmann, W. K., \& Gritz, E. R. (2003). How families communicate about HNPCC genetic testing: findings from a qualitative study. American Journal of Medical Genetics Seminars in Medical Genetics, 119C(1), 78-86. doi: 10.1002/ajmg.c.10010

Plumridge, G., Metcalfe, A., Coad, J., \& Gill, P. (2010). Family communication about genetic risk information: particular issues for Duchenne muscular dystrophy. American Journal of Medical Genetics, 152A(5), 1225-1232. doi:10.1002/ajmg.a.33364

Rapp, R. (2000). Testing Women, Testing the Fetus. London: Routledge.

Speice, J., McDaniel, S. H., Rowley, P. T., \& Loader, S. (2002). Family issues in a psychoeducation group for women with a BRCA mutation. Clinical Genetics, 62(2), 121-127.

Stefan, E.K. (2015). Gender differences in health information behaviour: a Finnish population-based survey. Health Promotion International, 30 (3), 736-745. doi: 10.1093/heapro/dat063

Suthers, G., Armstrong, J. McCormack, J. \& Trott. (2006). Letting the family know: balancing ethics and effectiveness when notifying relatives about genetic testing for a familial disorder. Journal of Medical Genetics, 43(8), 665-670.

Takeshima, K., Ariyasu, H., Ishibashi, T., Kawai, S., Uraki, S., Koh, J.,...Akamizu, T. (2018). Myotonic dystrophy type 1 with diabetes mellitus, mixed hypogonadism and adrenal insufficiency. Endocrinology, Diabetes \& Metabolism Case Reports, 2018, 
17-0143. doi:10.1530/EDM-17-0143

Theadom, A., Roxburgh, R., Rodrigues, M., O'Grady, G., Taylor, T., Baker, R.,...Feigin, V. (2016). Prevalence of genetic muscle disorders (DM1-Prev): a national, populationbased study. Neuromuscular Disorders, 26(2), S206. doi: 10.1016/j.nDM1.2016.06.436.

Troy A, \& Lewis-Smith, J. (2006). Preliminary findings on a brief self-disclosure intervention with young adult dating couples. Journal of Couple \& Relationship Therapy, 5(2), 57-69. doi: 10.1300/J398v05n02_04

Wellstead, P. (2011). Information behavior of Australian men experiencing stressful life events: the role of social networks and confidants. Information Research: An International Electronic Journal, 16(2). doi: http://informationr.net/ir/162/paper474.html

Wilson, B., Forrest, K., van Teijlingen, E., McKee, L., Haites, N., Matthews, E., \& Simpson, S. (2004). Family communication about genetic risk: the little that is known. Community Genetics, 7(1), 15-24.

Wiens, M.E., Wilson, B.J., Honeywell, C., \& Etchegary. H.A. (2013). Family genetic risk communication framework: guiding tool development in genetics health services. Journal of Community Genetics, 4(2), 233-42.

\section{Acknowledgements}

The authors acknowledge the generous support of the Neuromuscular Research Foundation Trust and the Richdale Charitable Trust, for the financial assistance which made it possible to return to New Zealand to conduct interviews.

The research presented in this paper was conducted while the first author was in training, completing her Master of Genetic Counselling. 
